\title{
Dung burning in the archaeobotanical record of West Asia: where are we now?
}

\author{
Robert N. Spengler III ${ }^{1,2}$
}

Received: 9 August 2017 / Accepted: 15 January 2018 / Published online: 31 January 2018

(c) The Author(s) 2018. This article is an open access publication

\begin{abstract}
In the early 1980s Naomi Miller changed the field of palaeoethnobotany; her research into whether the ancient seed eaters of southwest Asia were human or herbivore opened an ongoing debate over the impact that burning of animal dung had on the formation of archaeobotanical assemblages, and how researchers can differentiate between human and animal food remains. As the number of systematic archaeobotanical studies across West Asia and many other parts of the world increase, we are continually confronted with the question of the significance of dung burning. Herd animal dung is the dominant fuel source in many parts of West Asia today and the high densities of seeds of wild plants in archaeobotanical assemblages suggest that people were using dung as fuel across Inner Asia for millennia. Seed assemblages that represent herd animal dung are assisting scholars in understanding palaeoecology and herd animal diet in the past as well as human economy and pasturing practices. However, interpreting these assemblages is not always simple and there are predictable biases that need to be taken into account, notably an overrepresentation of endozoochoric seeds (seeds dispersed through animal ingestion). In West Asia, the most prominent of such seeds in dung assemblages are from the Amaranthaceae family, notably Chenopodium.
\end{abstract}

Keywords Central Asia $\cdot$ Archaeobotany $\cdot$ Palaeoethnobotany $\cdot$ Dung burning $\cdot$ Chenopodium $\cdot$ Fuel $\cdot$ Endozoochory

\section{Introduction}

In 1984, Naomi Miller and Tristine Smart published an article in the Journal of Ethnobiology, which contained a seemingly straightforward observation, also noted two years earlier in Miller's dissertation of 1982 and in Miller (1984). While working at the 3rd millennium BC archaeological site of Maylan, Iran, they theorized a novel interpretation for their macrobotanical data. In the article, they "suggest that seeds can be brought to a site incorporated in animal dung and become charred when that dung is intentionally burned as fuel" (Miller and Smart 1984, p 16). They presented the

Communicated by J. M. Marston.

Robert N. Spengler III

Spengler@shh.mpg.de

1 Max Planck Institute for the Science of Human History, (Max-Planck-Institut für Menschheitsgeschichte), Kahlaische Straße 10, 07745 Jena, Germany

2 Visiting Research Scholar, Institute for the Study of the Ancient World, New York University, 15 E 84th St, New York, NY 10028, USA idea that small seeds from wild herbaceous plants recovered at archaeological sites could be the remains of dung fuel, especially in arid or high-elevation parts of the world. Archaeobotanists were already well aware of the fact that the presence of seeds in an archaeobotanical assemblage does not necessarily mean that they (or the plants that they came from) were economically significant (Minnis 1981). Miller's seemingly simple, yet highly astute, observation has had profound ramifications on the field of archaeobotany around the world. In this article, I focus specifically on West Asia and adjacent regions, noting the impact that dung has had on archaeobotanical interpretations, and I discuss some of the ways this dung burning data is being used by researchers.

It has been a third of a century since Miller's seminal publication, and the majority of scholars in the field accept the role of dung burning in archaeobotany. However, human foraging practices or 'weed assemblages' are often discussed without properly addressing the issue of dung burning (discussed in Smith et al. 2015). People burn dung even when wood resources are available (personal observation), and it is safer to assume that seeds from wild plants in archaeological sites represent animal foraging, rather than human foraging, although disentangling these signatures is often impossible. 
Arguing for human foraging of seeds from small herbaceous plants in parts of the world where herd animal dung was traditionally burned as fuel requires additional proof, such as a cache of harvested wild seeds or recovering the seeds from a primary domestic context (essentially in a ceramic vessel or stomach of a desiccated human). While no one is arguing against human foraging in the past, the archaeobotanical record is not a simple one-to-one representation of these foraging practices. As the title of Naomi Miller's (1996) follow-up article in Current Anthropology implies, over a decade after she first published her observation, it is difficult if not impossible to determine whether the ancient 'seed eaters' at an archaeological site were 'human or herbivore'.

In her 1996 article, Miller not only went deeper into the dung discussion, she also illustrated what the ramifications for her observation were, largely by calling into question research at numerous sites in southwest Asia and weakening the foundation for the 'broad spectrum foraging theory'. This is a commonly cited theory for the origins of agriculture that suggests that humans were forced to widen their repertoire of foods during the end of the Pleistocene to include small grass seeds and smaller animals, as opposed to 'ideal' foods, such as the megafauna. Naomi Miller opened her article by challenging the data that were used to defend the theory that had first been postulated by Kent Flannery (1969). Building on Flannery's original argument, subsequent writers also argued that farming was first begun as a response to population pressure and the need to revert to lesser-ranked foods (Smith and Young 1983; Cohen and Armelagos 1984). While Flannery originally based his theory on archaeobotanical data from Ali Kosh, others expanded upon it, as new archaeobotanical data became available. Despite the fact that Helbæk (1969) actually noted burned animal dung at the site and almost no burnt wood in the Ali Kosh assemblage, no one called Flannery's (1969) interpretations into question for another three decades, rather the model was widely cited and continues to be so today (Stiner 2001; Zeder 2012).

Zooarchaeological data has failed to provide compelling supporting evidence for the broad-spectrum revolution in southwest Asia (Stiner 2001), and in other parts of the world, such as East Asia, fish, shellfish, and turtle remains are used to support the argument (Shelach-Lavi 2015), even though they are easily acquired, nutritious and desired foods (clearly not indicating low-ranking foods). Furthermore, Stiner (2001) uses shellfish and turtles as a "canary in the coal mine" (as a sensitive means of detection), noting that heavy use of these easily obtained foods during the transition to productive economies is directly in opposition to the broad-spectrum model. Compiling a massive synthesis of zooarchaeological data, Zeder (2012) demonstrated that the theory does not hold up, and some of the archaeological examples for a diversified range of foods come from areas with low population pressure and high resource abundance.
Archaeobotanical data sets such as that from Abu Hureyra have also been used to support the theory (Hillman et al. 1989), but these reports never confronted the dung burning issue. Hillman et al. (1989) dismissed the possibility of dung burning at Abu Hureyra on the grounds that carbonized fragments of actual dung were not recovered, but finding the full carbonized matrix of dung is rare, and often only carbonized seeds are recovered. They also use the argument that "[w]oody fuels would have been plentiful close to Abu Hureyra, so there would have been no need to burn dung in any case" (Hillman et al. 1997, p 652) and that certain seeds recovered in the assemblage were inedible to herd animals. However, ethnographic observations show that wood availability does not exclude the use of dung as fuel and many of the seeds cited as inedible to herd animals are readily consumed, although they would be inedible to humans, so such observations further disprove the broad-spectrum foraging theory. While there is currently little evidence to support the broad-spectrum theory, it is still readily propagated in the literature and Miller's critique is often overlooked.

\section{Dung fuel in West Asia}

Dung is a significant part of the daily economy for many traditional peoples today, and it was clearly important in the past (Fig. 1). Dung is almost universally important among herding economies (as well as for many agropastoralists), including peoples in high-elevation South America, the Great Plains of North America (from bison), essentially all of Europe, North Africa, much of South Africa, southwest Asia, other parts of South Asia (notably water buffalo and cow in India), all of Central Asia, northeast Asia, and far northern Eurasia (yak and reindeer in Siberia and the tundra region). Dung collecting is often a gendered and usually a daily activity, especially where dung is the main fuel source. Dung is often burned many times a day for heating and for cooking. Humans on at least five continents collect dung from a variety of different herd animals. In addition, there are many recorded accounts of people using dung from wild animals for fuel, notably from wild ungulates such as North American bison. I will only briefly touch on a few accounts from West Asia here, because the copious ethnographic literature is too vast to fully address.

Early explorers and ethnographers in Central Asia and its adjacent regions noted the importance of dung as a source of fuel before the introduction of coal or natural gas (Cunningham 1854; Doughty 1921; Teichman 1921; MacDonald 1929; Poklonskii et al. 1953 [1897]; Lewis 1958; Ekvall 1968; Rye and Evans 1976). A closer look at these historical sources can tell us much about the nature of the economy in Eurasia through time. While on an expedition across the Arabian peninsula, the explorer Doughty noted that camel 

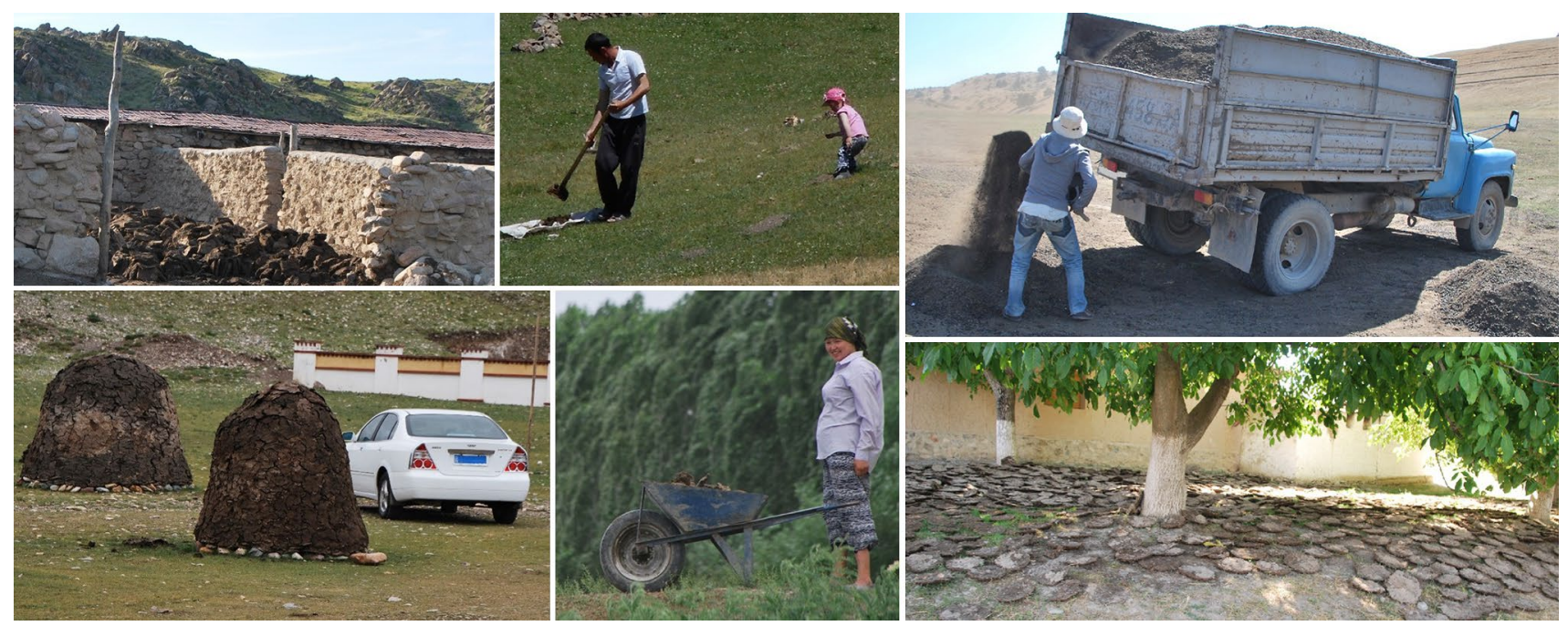

Fig. 1 Ethnographic images of dung collecting and drying. Upper left, drying bricked-up sheep and goat dung in a modern Kazakh winter camp in the Bryan-Zherek valley of eastern Kazakhstan, in the summer of 2011, when herds were pasturing in the mountains; upper centre, Uzbek herder and his daughter collecting cow dung as part of their morning routine near the Tashbulak archaeological site in 2015, eastern Uzbekistan; upper right, dung collectors from the more densely populated lower-elevation regions of Uzbekistan tak-

dung collected from the desert was essential for cooking and heating at night (Doughty 1921, pp 305-305). Ekai Kawaguchi, a Japanese explorer who travelled around the Tibetan cultural region in the early 1900 s, noted that yak dung was at the centre of the local economy. "In Tibetan wilds the only kind of fuel accessible to travellers (except of course dead leaves of trees for kindling purposes) is the dry dung of the yak (these animals being set loose to graze for themselves) and the kyang [Equus kiang], a species of native wild horse" (Kawaguchi 1909, p 91). He mentions gathering wild horse and yak dung numerous times throughout his writings, pointing out that in some areas it was purchased (p 113) and that the only thing it was not good for was human cremation, because the fire would not burn hot enough (p 389). Other early explorers made similar observations while travelling across the Himalaya. For example, Eric Teichman (1921) served as a consular officer to the north of the plateau and in his reports he mentions making fires out of yak and cattle dung. The ethnographer Ekvall (1968) emphasizes the importance of dung fuel in the domestic life of the aBrog $\mathrm{Pa}$ pastoralists in northeastern Tibet. A British ethnographer and explorer of the mid 19th century, Alexander Cunningham (1854), studied the people of Ladak in Tibet, stating that "in a country where fine wood is so scarce as not to be obtained by any but the richest classes, all kinds of dung are in daily use as fuel, and but little can be spared for enriching the land" (p 222). He further emphasizes the fact that wild animal dung was also used ( $p$ 219). In the travel accounts ing truckloads of sheep and goat dung from the mountain foothills to sell in markets in 2017, near the archaeological site of Tashbulak; lower left, yak dung heaps in Tibet along the route to Namsa lake not far from Lhasa, in 2010; lower centre, young Uzbek woman collecting cow dung outside Samarkand in 2013; lower right, gathered cow dung drying under walnut trees in a rural region of the Uzbek lowlands along the river Zerefshan in 2017

of the French priest, Abbé Éváriste Régis Huc (1860), he elaborated upon many uses of dung in the Himalaya, including the practice of building beds on top of slow smouldering dung fired stoves to keep warm at night.

While travelling through Central Asia and Pakistan towards Bukhara in the early 19th century, Lieutenant Alexander Burnes noted, in a proper British colonial fashion, that he was forced to collect the dung of their camels in order to heat his daily tea (Burnes 1834, p 253). While in Tashkent in 1877 , Eugene Schuyler noted that herd animal dung was the main fuel of the steppe and in several cases talked about fires built with a combination of wood and dung fuel (Schuyler 1877, p 320). Likewise, while passing across the Iranian plateau on his way to Merv, O'Donovan (1883) noted the use of dung fuel. Further north in Central Asia, 19th century pastoralist groups, such as the Yakuts, relied so heavily on dung as a vital part of their economy that they used it to construct the roofs of their houses, like a well-insulated mortar (Poklonskii et al. 1953 [1897], pp 344-357). They also formed large bowls with wet dung in the winter that could be used, once frozen, as moulds in which to freeze fermented milk blocks (Poklonskii et al. 1953[1897]). Similarly, dung was sometimes mixed into clay to serve as a binding agent (temper) when making pottery. Across West and South Asia, dung is employed as a binder in mudbricks, being easier to obtain and work than crushed straw or chaff, and is also used in floor and wall plaster. Mudbricks from archaeological sites in West Asia tend to contain impressions of finely crushed 
plant remains, notably grass culms and blades, and many of these impressions probably represent dung used in making them. Dung is also one of the best fuel sources for firing pottery. Villagers in Pakistan traditionally used a combination of dung and straw when firing pots (Rye and Evans 1976, p 38) and for cooking (Madella 1997). In northern India, "cattle are of crucial significance in the village because of their dung" (Lewis 1958, p 40). In the travel accounts of Ambrosio Bembo around 1672, he noted that the people of northern India feel a maternal connection to their bovine companions, who provide them with milk and dung (Bembo 2007). Ethnographers working among village women in the late 1950s in northern India and Pakistan noted that they preferred dung to wood because it burned at a low temperature for a long time; hence, a meal could be placed over a dung fire and the cook could then head to the fields to work (Lewis 1958; see also; Reddy 1999; Vaňkát et al. 2010), but cooking with a wood fire often burnt the food and cracked the pots; this has changed with the introduction of brass cooking pots. In fact, an ethnographic study in 2000 suggested that the use of dung as fuel in India was a 1.5 billion dollar industry, comprising the equivalent fuel use of 43 million tons of coal (Harris 2000).

More recent ethnographic work in Central Asia proper also mentions the use of dung as fuel and the practice of dung collecting. Interviews from across the region by travellers, both explorers and scholars, record accounts of people, often women, collecting dung and carrying it over long distances as part of their daily routine (Anderson and ErtugYaras 1996; Miller 1996; Féaux de la Croix 2016, p 220). Notably, there are a number of more recent ethnographic studies that mention dung use, especially yak dung, in western China (Rhode et al. 2007a). While doing ethnographic interviews among Kurdish agropastoralists in Iran, Kramer claims that she was informed that the herders believed that the most important secondary product that they obtained from their animals was dung (1982, pp 45, 47). Patty Jo Watson, while doing archaeological ethnography in western Iran, noted that dung was gathered across the entire area that the animals grazed (1979, p 122). While working on archaeological projects in Kazakhstan, I observed herders using a combination of riparian Populus and Salix wood as well as cattle, sheep and goat dung as fuel. The sheep and goat dung, despite consisting of small pellets, was actually easier for the herders to collect than cattle dung. These herders pen their animals at night to protect them from predators and keep them from wandering; the floors within these pens build up a thick layer of dung after repeated nightly penning events. Most Central Asian pastoralists return to the same pasturing grounds every year, which means that the pen from the previous summer will consist of a dry bed of pressed sheep and goat dung that can easily be made into bricks for burning.
One of the best ethnographic discussions of dung use in inner Asia comes from Fields on the hoof: Nexus of Tibetan nomadic pastoralism (Ekvall 1968). Ekvall notes that Tibetan herders rely on their animals for: (1) meat; (2) milk (fresh and fermented milk, yogurt, fresh and fermented butter, cheese and whey); (3) blood, which is tapped from veins in the necks or shoulders of cows and yaks without killing the animal and coagulated before serving; (4) hair, which is pulled from yaks and the belly fringes of yak/cow hybrids when they start shedding it in the spring; (5) by shearing, which is done on yak/cow hybrids, the manes and tails of mares, as well as sheep and goats; (6) hides for rawhide, leather, or sheepskin fleece; and (7) for producing dung. He notes that the collection of dung from all animals, wild and domesticated, is the most important of all of these uses. He points out that it is a daily chore, and usually the role of the women, as keepers of the hearth; however, men will help with collecting the dung for winter storage and for sale to the Buddhist monasteries. He also notes that the dung is collected wet in the summer so the rain does not wash it away, and wet dung is easily moulded or smeared for drying in sheets or storage as a heap or in bricks. He further notes that dung is preferred to wood as fuel, even when wood is available, and cow dung is the most frequently used, but that sheep dung gives the greatest heat in proportion to volume. In fact, dung is so important among high-elevation populations of inner Asia that Rhode et al. (2007a) provide a compelling argument that yaks may have been one of the key variables in the successful colonization of the Himalayan plateau by sedentary people, due to their need for heating and cooking fuel. However, it should be noted that this colonization process started at least a millennium before there is clear evidence for yak domestication.

\section{The archaeology of dung}

Since dung is such an important part of the economy for people all over the world, it is not surprising that a large number of studies of archaeological dung have been approached from very different vantage points. While this article focuses on dung burning signatures in macrobotanical assemblages from West Asia, it is worth briefly synthesizing here the broader field of the archaeology of dung. The analysis of macrobotanical remains can be used to identify the burning of dung as fuel in archaeological sites (discussed more below); however, the preservation of the seeds in this case relies on carbonization. There are many economic uses of dung that do not lead to carbonization. In some cases, dung can be identified through other archaeological means, such as impressions in mudbrick or pottery or from desiccated remains. However, when these methods are not sufficient, 
archaeological scientists have come up with a range of ways to identify a dung signature in sediments.

One of the more reliable means of identifying a dung signature in sediments is through the study of spherulites, fibrous crystalline aggregates of calcium carbonate from the guts of ungulates (Brochier et al. 1992; Canti 1997, 1999; Shahack-Gross and Finkelstein 2008; Lancelotti and Madella 2012). Studies of spherulites can provide a direct indication of dung, and they have been identified at the early farming site of Jeitun in Turkmenistan (Canti 1997). However, recent studies have shown that they do not reliably form in the digestive systems of herbivores, and biologists do not know much about their formation processes. Researchers have not been able to correlate specific soil conditions or diet to the formation of spherulites, and their production rates may be linked to the specific physiology of an animal. Therefore, even though the presence of the round calcium deposits is a direct indication of dung, their absence does not equate with no dung present. One recent experimental study of dung burning only recovered very low frequencies of these calcium deposits, arguably too low to be a reliable indicator in archaeological sediments (Lancelotti and Madella 2012). Furthermore, since spherulites are made of calcium carbonate, they dissolve in certain soils, notably in highly moist or high $\mathrm{pH}$ conditions.

While there are a wide range of chemical element changes in soils that can be enhanced by dung, notably enriched levels of carbon, calcium, nitrogen, phosphorus and sodium, these chemical changes are short-lived and are useless from an archaeological perspective (Evershed et al. 1997). Experimental studies that have attempted to identify higher levels of these elements failed to recognize increased amounts of anything other than potassium (Evershed et al. 1997, p 492), and in other studies, manuring is linked with low levels of potassium (Holliday and Gartner 2007). These studies also find contradictory results for phosphorous-“" $[t]$ his observation must cast serious doubts on the use of total phosphorus as an indicator of manuring in this type of soil" (Evershed et al. 1997, p 493). However, high phosphorous (P) levels in sediments are still readily used as indicators of manuring or for the presence of dung (Simpson et al. 1998) because of their immobility in soils (Holliday 2004; Holliday and Gartner 2007). Nonetheless, an experimental study of burying bones for 33 years to study changes in soil chemistry showed that soil phosphorus levels are not always increased by human activity, for example, phosphates do leach out of highly sandy soils and certain soils that lack suitable P-receptors (Crowther 2002). Bogaard et al. (2007) suggested that elevated levels of $\delta^{15} \mathrm{~N}$ in archaeobotanical remains of cereal grains can be used as an indication that the crops were grown in manured fields. Several studies have relied on nitrogen isotope levels to identify herd animal enclosures and crop manuring (Simpson et al. 1999; Shahack-Gross et al. 2005).

In the absence of phosphates, a few scholars have proposed the use of lipid biomarkers linked to coprostanols and bile acids (Evershed et al. 1997; Simpson et al. 1998; Bull et al. 1999). One promising route for using biomarkers to identify herd animal dung seems to reside in the presence of $5 \beta$-stanols in sediments (Evershed et al. 1997). Coprostanol

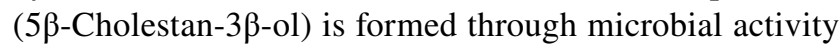
from cholesterol in the gut (Bull et al. 1999; Shillito et al. 2011), although, the parameters of preservation for these two categories of biomarkers are not well understood and wellpercolated sediments, clay content, and temperature may impact preservation (Linseele et al. 2013). Another proposed method is the identification of microorganisms associated with dung. There have been a number of studies of human cesspits that have focused on the detection of intestinal parasite eggs. Similarly, the study of predatory mites in the Gamasida order has been suggested as a way to identify herd animal dung in sediments (Schelvis 1992). While the use of endoparasite ova is proven for human and carnivore palaeofaeces, further work is needed to understand their usefulness in identifying ungulate dung (Reinhard 1992). Spores from faecal-specific fungi can also suggest the presence of dung (van Geel 2001).

High densities of phytoliths have also been used to argue that dung is present in sediments. A few of these studies have gone so far as to argue that it is even possible to differentiate between different herd animal species based on the types of phytoliths present in the archaeological sediments (Powers et al. 1989; Eksambekar and Kajale 2007), although Shahack-Gross et al. (2005) dispute this possibility. Recent experimental work found widely diverging concentrations of phytoliths between modern dung samples, suggesting that the concentration of phytoliths in dung as well as in sediments is more a reflection of ecological conditions and the kinds of plants consumed (Lancelotti and Madella 2012). Furthermore, densities of any botanical remains in sediments tend to reflect overall rates of sediment accumulation, which are controlled by a wide range of both natural and humaninfluenced depositional processes. However, Lancelotti and Madella (2012) do suggest that certain categories of phytoliths may allow researchers to identify a dung signature, even if overall densities are not a reliable method. They note that in their experiments high densities of 'grass leaf/culm' phytoliths were present, whereas the categories 'grass inflorescence' and 'woody species' were very low (collectively around 1 or $5 \%$ of the assemblage). This observation may suggest a promising future approach using phytoliths; however, this evidence is highly ecologically specific and may not apply in all circumstances.

As with most studies in the archaeological sciences, the clearest interpretation can be drawn from multiproxy 
approaches, and a few approaches to the archaeology of dung have used multiple datasets (Simpson et al. 1998; Matthews 2010; Shahack-Gross 2011; Lancelotti and Madella 2012; Elliott et al. 2015; Smith et al. 2015). As with all of these methods, there is a need for control samples from offsite, in order to determine background readings (Lancelotti and Madella 2012, p 962). Each method has its own merits and allows scholars to ask specific questions. For example, phosphate surveys help with the identification of old occupation sites or locations where phosphates built up over longterm human occupation and pastoral activity. However, phosphate and nitrogen levels are often a better indicator of bone decomposition and require extended periods of occupation on the same spot to build up. It is not clear how such methods would be implemented across much of West Asia, where sites are often easily identified because they were located and relocated in specific micro-environmental settings repeatedly for millennia (Spengler et al. 2013a, b; Spengler 2014). Furthermore, questioning whether dung was present at a mobile pastoral site with dense remains of domesticated animals and in many cases identifiable pens in the stratigraphy should not be necessary. Still, some valid inquiry can revolve around questions related to the manuring of agricultural fields or intensity of penning and herd composition.

\section{The archaeobotany of dung burning}

Understanding the impact that dung burning had on the formation of archaeobotanical assemblages is vital to any macrobotanical study in West Asia that addresses regional ecology, herding practices, climate and diet. Numerous articles have dealt with carbonized dung remains from archaeological sites (Miller 1982, 1984; Bottema 1984; Miller and Smart 1984; Pearsall 1988; Miller and Gleason 1994; Miller and Marston 2012).

\section{Dung burning experiments}

While working in Malyan, Iran, Miller (1984) conducted the first experimental archaeology studies of dung; she collected four samples from the modern village where she already knew the basis of the local dietary economy-one from a hearth, two from middens and one from a fire pit (Miller and Smart 1984). Cattle dung and willow branches were burnt in the hearth and its ash contained seeds from small wild herbaceous plants. The samples from the first midden deposit contained carbonized wood as well as 764 charred seeds, of which only 16 were from domesticated plants (Miller 1984). A number of follow-up dung burning experiments have been done around the world, across Europe and southwest Asia (Madella 1997; Charles 1998; Reddy 1999; Shahack-Gross et al. 2005; Valamoti and Charles 2005; Miller 2009; Shahack-Gross 2011; Braadbaart et al. 2012) as well as in the Americas (Hastorf and Wright 1998). Spengler et al. (2013b) conducted a similar experiment in eastern Kazakhstan; they collected 201 of cattle dung from the area around a modern herder's pens near Taldy-Kurgan and burned it in an enclosed fire pit. The Taldy-Kurgan dung burning experiment required about three hours to burn the dung down to $18.51 \mathrm{~g}$ of ash. In the laboratory, 1,291 seeds were identified in that ash (not including the 271 unidentifiable fragments); none of the seeds were larger than $2 \mathrm{~mm}$. As with the observations made in other dung burning experiments, a mixture of carbonized, uncarbonized and partially carbonized seeds was recovered. Chenopodium spp. was also noted as the most abundant seed category in the assemblage, represented by 641 seeds or seed fragments (roughly $50 \%$ of the total assemblage), despite the fact that it was not overly common in the general landscape around the site (Spengler et al. 2013b) (discussed more below).

Valamoti and Charles (2005) conducted, arguably, the most informative dung burning experiment, tracing the chain of production back to the animal feed, followed up with more detailed studies by Valamoti (2013) and Wallace and Charles (2013). They fed two goats einkorn and figs and collected the dung pellets over several days. Interestingly, despite directly feeding the animals with grains, the seed assemblage was dominated by wild plants, notably Amaranthus sp. and Chenopodium album. These were growing around the area where the animals were tethered. The authors noted that a single goat pellet could contain as many as three fig seeds, three wheat glume fragments and 20 wild seeds and that the animals produced roughly 300 pellets per day (Valamoti and Charles 2005, p 530). A later study, averaging dung pellet production from eight sheep over 5-6 days, counted about 500 pellets per day with a range between 400 and 1,100 (Wallace and Charles 2013). However, the most interesting observation, from an archaeological point of view, was the fact that domesticated grains did not survive the digestive process. The glume wheats were identifiable after digestion only from fragments of their glume bases; a similar study with hulled barley noted that its glumes survived the digestive process, resulting in 'sucked' and compressed grains (Charles 1998). Therefore, free-threshing grains would not be visible at all, and we can assume that dung burning would reduce the overall representation of agricultural crops and many field weeds in archaeobotanical assemblages, both by destroying any grains that were used as fodder and also by over-representing seeds from wild herbaceous plants.

In a continuation of these detailed experimental studies, dung pellets collected from a goat that had been fed einkorn grains were carbonized (Valamoti 2013). The resulting ash contained spikelet forks and glume bases from the wheat, which showed that the burning of dung from foddered 
animals leads to assemblages rich in rachises and glume bases. Valamoti went a step further, by analysing the glume bases in the dung before and after carbonization; she noted that the post-digestion examples possessed a 'rugged' surface. The most important ramification of this observation is that it further calls into question whether seeds of wild plants, even if they are found in accompaniment with chaff, can ever be ascribed confidently to the category of 'field weeds'. As Wallace and Charles (2013) point out, most of the animals from which dung fuel is derived have ruminant digestive systems, with a few mono-gastric exceptions, such as the equids (horses etc.); hence, the digestive process is long and highly destructive. They also performed a systematic dung burning experiment, collecting fresh sheep pellets from animals that were fed known diets; they found that cereals and tubers are rarely identifiable after digestion, but certain kinds of small wild seeds are highly prevalent. While not actually a dung burning experiment, the experimental work by Schepers and van Haaster (2015) is extremely informative. They fed cows, sheeps and goats with hay from a known field on which they had run botanical transects, and quantified the resulting seeds in the dung to see if they were representative of the plant community growing in the field. They noted that the presence or absence of seed categories in the dung served as a sufficient indicator of the local vegetation, but that there were too many variables involved in absolute seed counts to use them as indicators of plant populations in the fields.

\section{Identifying a dung burning signature}

In many archaeological sites in arid parts of the world, such as southern Central Asia and the Iranian plateau, carbonized fragments of actual dung are preserved (Fig. 2); similarly, some high-elevation sites contain preserved yak dung (Rhode et al. 2007b). Quality dung preservation allows for the identification of the animal that produced it, such as when entire sheep or goat pellets are preserved. However, carbonized dung often looks like a mass of, or small pieces of, plant material or fibrous tissue, often with fragments of grass culms and blades visible. Often these fibrous masses
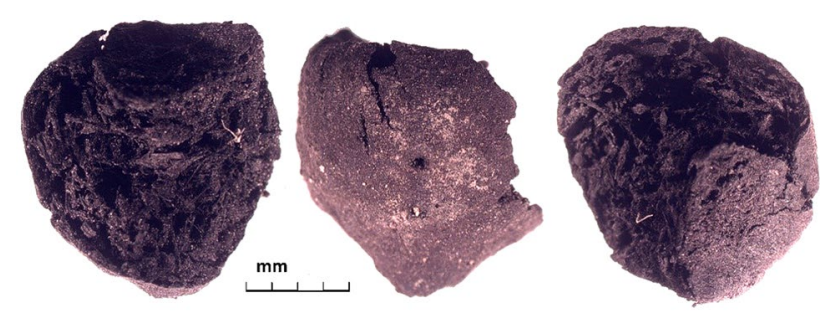

Fig. 2 Three views of a carbonized sheep or goat pellet from FS 37 at the archaeological site of Tashbulak (ca. AD 1100) in the mountains of Uzbekistan have visible seeds in them (Spengler 2013); however, in other cases seeds are completely absent in the dung (Rhode et al. 2007b; Ghosh et al. 2008), which opens up questions relating to the seasonality of seed assemblages from dung burning. One of the reasons that archaeobotanists are hesitant to accept that the assemblages that they are studying represent dung is because few sites allow for preservation conditions good enough to actually retain articulated fragments of it. After flotation, most archaeobotanical assemblages simply consist of carbonized seeds and wood fragments; the dung matrix breaks away from the seeds and is lost. In this regard, it becomes even more difficult to determine how the seeds were introduced into the assemblage. Ultimately, even if whole fragments of dung are not preserved in the archaeobotanical assemblage, dung burning could still have been the prime factor in the creation of that assemblage.

While working on archaeobotanical material from the site of Begash, Kazakhstan, from occupation layers dating between the late 3rd and 1st millennia BC, Spengler et al. (2013b) argued that the majority of the wild seeds in the assemblage came from the burning of dung as fuel, despite the fact that there were no remains of articulated dung found in the entire assemblage. They made seven observations, relating to similarities between their experimental study and actual archaeobotanical assemblages from the region; they all had: (1) high frequencies of seeds of herbaceous plants; (2) small seeds $<2 \mathrm{~mm}$; (3) low abundance of wood; (4) similarities in the actual seed categories present; (5) similarities in which categories were abundant; (6) presence of partially carbonized and uncarbonized seeds mixed in with carbonized ones (although uncarbonized seeds rarely preserve archaeologically) and (7) a high level of fragmentation of seeds and fruits (Spengler et al. 2013b).

Several archaeobotanists working in central and southwest Asia have used similar arguments; for example, low abundance of wood fragments $>2 \mathrm{~mm}$ is often used to argue that dung was used as fuel (Miller 1984; Klinge and Fall 2010; Miller and Marston 2012), and the argument is strengthened when coupled with high abundances of seeds from small wild herbaceous plants. This argument, or a similar one, was made by Miller (1984) while working in southwest Asia and later by Klinge and Fall (2010) on the Iranian plateau, who reconstruct human/environmental impacts. Although in an arbitrary category, high counts of unidentifiable seed fragments in an assemblage or generally fragmentary seeds have also been used as another supporting line of evidence to suggest that the prime means of seed incorporation was dung burning (Spengler et al. 2013a). However, determining the degree of fragmentation is qualitative and relies largely on the confidence level of the sorter; the quality of preservation is also often due to later taphonomic processes rather than mastication and digestion by ruminants. 
There are also two biases in dung burning assemblages that can be used to help interpret the archaeobotanical record and which need to be addressed when using the resulting data. First, seeds with hard outer coats tend to be over-represented in assemblages from burnt dung (the inverse is true as well); and second, toxic or naturally protected seeds (with anti-herbivory defences) should not appear in the assemblages. The bias towards specific kinds of seeds that preserve despite mastication, digestion, carbonization and biotic and abiotic deterioration has not been explored in detail. While most ungulates graze on small herbaceous plants, supplemented by some browsing of branches and tree leaves, not all of those plants produce seeds that will ultimately become incorporated into the archaeobotanical record. Seeds with hard seed or fruit coats (testa or pericarp) are more likely to be recovered post-digestion. To this end, archaeobotanical assemblages from Central Asia tend to be dominated by hard-coated seeds like Chenopodium or Lithospermum (for examples, see Spengler 2013; Spengler et al. 2013a, b). However, some soft-coated seeds are often reported, such as Hyoscyamus from the sites of Begash (Spengler 2013) and Tuzusai (Spengler et al. 2013b) in Kazakhstan. While the abundance of seeds with hard testae helps support the argument that most of the wild seeds in Central Asian archaeobotanical assemblages are the result of dung burning, there are two other factors to consider: (1) the preservation of hard testae is also biased by taphonomic processes; and (2) hard seed coats are also an adaptation to dry environments and plants that produce them are therefore abundant in many regions of West Asia.

There have also been a few attempts to identify dung burning signatures based on the categories of biological remains that are present in sediments, notably theorizing what kind of archaeobotanical remains represent dung (Charles 1998; Hall and Kenward 1998).

Gordon Hillman and his colleagues (1997, pp 651-652) claimed that one of the ways to determine that wild seeds in an assemblage are not the result of dung burning is by the presence of seeds that could not be consumed by herd animals. Theoretically, this method would show that at least some of the assemblage formed from sources other than the burning of dung. They note that certain seeds are either too hard for herd animals to consume or too toxic. They use the hard florets of Stipa, with their helically coiled awns, wild cereals, notably Triticum and Secale spp., and the thick siliceous coats of Boraginaceae seeds to support their argument, stating that the abundance of these seeds in the archaeobotanical assemblage from Abu Hureyra in Syria is evidence that the wild seeds were not from herd animal dung (pp 651-652). While it is true that the florets of certain species of Stipa can injure grazing animals (Hitchcock 1951, p 445; Miller 1997, p 656), the grasses are readily consumed by herd animals in Central Asia and Stipa plants are one of the key forage sources. The Hyoscyamus niger plant contains alkaloids that are reported as being toxic to herd animals (Roberts and Wink 1998; Stegelmeier et al. 2007; Majak et al. 2008, p 58), hence its vernacular name 'henbane'. Seeds from this plant have been recorded in several archaeobotanical assemblages from Central Asia (Spengler 2013). However, I have personally observed local Kazakh herders' goats, near the town of Taldy-Kurgan, consuming an entire henbane plant including its ripe and unripe fruits (which I was monitoring with the intent of collecting it for comparative material) during the summer of 2008 , with no apparent ill effects. Therefore, a better understanding of herd animal grazing and browsing habits is required before we can use the presence of solanaceous plants as indicators to argue against dung burning.

\section{Archaeological significance of dung burning assemblages}

A careful study of the remains of burned dung from archaeological sites can lead to a better understanding of human economy, notably dietary patterns (Shahack-Gross and Finkelstein 2008). The burned dung signature can also help researchers build a stronger interpretation of past resource utilization, conservation and reconstruction of environment and mobility patterns. For example, it has sometimes been claimed that it is possible to partially reconstruct the diet of herd animals from the seeds preserved in dung ash (Ghosh et al. 2008; Linseele et al. 2010; Marinova et al. 2013). In particular, dung assemblages are good for identifying foddering when hulled or glumed cereals were used or when chaff was fed to animals after grain processing. In this sense, dung remains can answer questions regarding herd animal maintenance and penning. One noteworthy study was conducted by Derreumaux (2005), who used dung burning assemblages to identify foddering practices at the Roman site of Le Marais de Dourges in France. Also, Veal (2013) argued that in the heavily overgrazed and dry Mediterranean landscape during the Roman period, dung was a central component in the economy. Spengler et al. (2013b) discussed the importance of dung burning in the prehistory of Central Asia, using the data to reconstruct herding practices. Valamoti (2007) even used dung burning data to help explain differences in site formation processes in the Neolithic of northern Greece, claiming that two distinct economic populations existed in the region, each using different herding strategies and ultimately leaving different archaeological footprints.

The choice of dung as fuel, especially when wood resources were available, says much about preferences in technological and social traits (Sillar 2000). While working at the site of Maylan in the river Kur basin of the Zagros 
mountains in Iran, Miller (2004) identified a decrease in charcoal abundance and a corollary increase in wild seed abundance during the 3rd millennium BC. She argued that this pattern suggested a decrease in the availability of wood resources for fuel and a greater reliance on dung burning, possibly indicating increased reduction of woodlands (Miller and Marston 2012). Spengler et al. (2013b) noted that the main seed components in the burnt dung assemblages that they studied from northern Central Asia were from plants that needed more moisture in their environment than is available in most of the region today. Many of the plants, notably Chenopodium spp., are also indicators of disturbed environments around pastoral camps. Therefore, they argue that herd animals were grazing on localized pockets of rich vegetation that had been enhanced and maintained by pastoral activities in the past, just as they are by herding activities today. The process of herd animal grazing increased the plant nutrients in the soil around herding camps and selected for a vegetation community that was both highly nutritious for herd animals and tolerant of heavy grazing pressure (Spengler 2014).

Another interesting palaeoecological study using dung data from Central Asia comes from Xinjiang, China, where desiccated sheep/goat pellets were recovered from a burial dating to roughly $400 \mathrm{BC}$ (Ghosh et al. 2008). An analysis of both pollen and phytolith remains in the dung (seeds were largely absent), indicated a wide range of plants, mostly grasses and several water-demanding plants. The data illustrate that the environment in the local region, where the animals grazed, was more temperate than most of the area is today. Song et al. (2017) not only identified dung burning remains at the mid 1st millennium AD site of Kaerdong in western Tibet, they also noted large dung fragments with seeds still visible in the matrix. They used this data to reconstruct grazing practices at the site, noting that the high elevation (4,300 $\mathrm{m}$ a.s.1.) herd animals, probably yaks, were grazed on a marshy location near the site.

\section{Archaeobotanical Chenopodium seeds in Central Asia}

The Chenopodium genus provides a great case study for discussing the human versus animal foraging argument in Central Asia. Chenopodium spp. are often the most prevalent seeds of wild plants in archaeobotanical assemblages from sites across northern Central Asia through time (Table 1; Fig. 3). In many cases, they outnumber domesticated grains and often range between 25 and $50 \%$ of the total assemblage. Chenopod seeds tend to dominate archaeobotanical assemblages across eastern Central Asia, as seen in Fig. 3, as well as western Central Asia (Anthony et al. 2005; Rühl et al. 2015). Therefore, it is not surprising that there has been some inquiry into whether they could represent human foraging practices; however, as I noted above, disentangling
Table 1 Seed counts from select archaeobotanical assemblages from northern Central Asia spanning a range of ecological zones and time periods: Begash (Iron Age), 390-50 cal BC; Begash (Bronze Age), 2460-1700 cal BC in eastern Kazakhstan (Frachetti et al. 2010; Spengler 2013); Tasbas, 2832-1054 cal BC in eastern Kazakhstan (Spen- gler et al. 2014; Doumani et al. 2015); Tashbulak, ca. AD 1000 in eastern Uzbekistan (unpublished results); Tuzusai, 410-150 cal BC (Spengler et al. 2013a); and the experimental dung burning data from Spengler et al. (2013b)

\begin{tabular}{|c|c|c|c|c|c|c|}
\hline Sites & $\begin{array}{l}\text { Begash (iron } \\
\text { age) }\end{array}$ & Begash (bronze) & Tasbas & Tashbulak & Tuzusai & Experimental fire \\
\hline Domesticated & 54 & 34 & 1,477 & 205 & 2,306 & \\
\hline Wild & 651 & 1,442 & 3,129 & 3,560 & 666 & 650 \\
\hline Chenopodium & 160 & 1,043 & $540^{\mathrm{a}}$ & 2,094 & 187 & 641 \\
\hline Fruits/Nuts & & & & 198 & 4 & \\
\hline Total & 865 & 2,519 & 5,146 & 6,057 & 3,163 & 1,291 \\
\hline
\end{tabular}

${ }^{a}$ The percentage of the wild seeds represented by Chenopodium at Tasbas is low because 2,335 Vaccaria seeds were recovered, presumably preserving through the digestive process as well

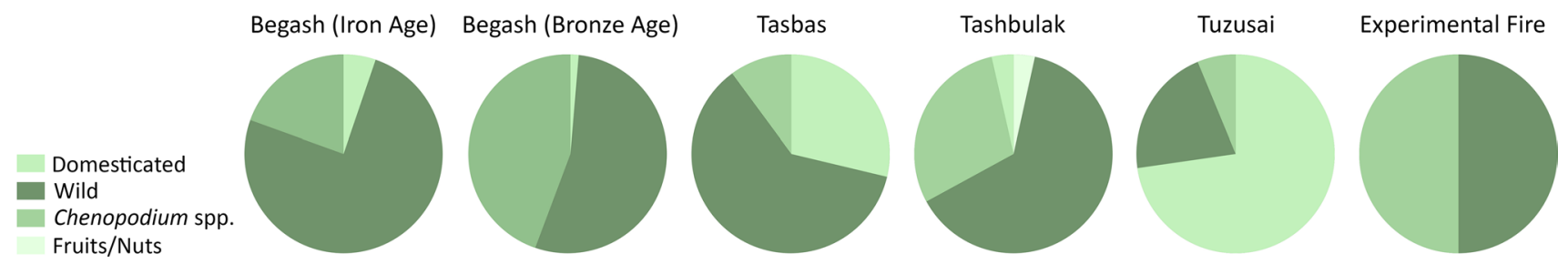

Fig. 3 Pie charts displaying the data from Table 1 
human and herd animal foraging practices is often impossible when dung burning is considered. The seeds are adapted to being dispersed in dung and are therefore well evolved to withstand mastication and digestion; they also have high dormancy rates and can survive extended periods in the soil seed bank even without carbonization.

Numerous Amaranthaceae taxa have attracted human attention around the world, in many cases resulting in domestication. Chenopodium giganteum (album complex) cultivation may date back to ca. $2400-1900$ BC in eastern China, and its grains and greens were collected from the wild as food for millennia (Anderson 2014; Lu et al. 2016). Ethnographic sources from Europe and Russia also note the importance of the plant and its seeds as a wild food source. In most archaeobotanical assemblages from northern Eurasia, Chenopodium spp. seeds are the most abundant category, often outnumbering any cultivated crops, so it is not surprising that some questions have been raised about possible foraging of wild plants by humans. However, with the difficulties disentangling dung burning and human foraging indicators, it is worth discussing the plants in this genus (and the entire Amaranthaceae family) further. Russian archaeologists have specifically claimed that this 'pseudo-cereal' was collected by early Iron Age people in the Minusinsk basin in the Altai mountains (Bokovenkov 2006). It has been suggested that the abundance of the seeds at the sites of Krasnosamarskoe and the herding camps of Peschanyi Dol 1, 2, 3 and Kibit 1 in the Samara valley in the Volga region during the 2nd millennium BC suggests that Chenopodium was collected from the wild (Anthony et al. 2005; Popova 2006). Other archaeologists have drawn similar conclusions (Motuzaite-Matuzeviciute et al. 2012; Rühl et al. 2015). While we cannot and should not dismiss the possibility that early people in Central Asia were using chenopod greens or seeds as a food source, which they probably were according to ethnographic analogies, we also should not assume that the presence of the seeds in an archaeobotanical assemblage necessarily indicates human foraging patterns.

In the experimental dung burning work by Wallace and Charles (2013) mentioned earlier in this paper, C. album dominated the assemblage. In fact, only four wild taxa were identified among the seeds in the dung, two of which were from the Amaranthaceae family, and roughly $90 \%$ of the wild seeds were $C$. album. They noted that " $[\mathrm{t}]$ he prevalence of Chenopodium album in small ruminant dung highlights its tenacity in surviving digestion even if consumed in modest amounts" (2013, p 26). They further note that endozoochory studies have emphasized the fact that seed size and seed-coat thickness are the two most important factors in seed survival through the digestive process. Spengler et al. (2013b) also noted very high abundance of Chenopodium seeds in their dung burning experiment in Kazakhstan, despite the fact that the landscape was highly biodiverse, dominated by grasses, notably Stipa spp., while Chenopodium plants were largely restricted to old herd animal pens. Hence, it actually appears that herd animal digestion concentrates and leads to an over-representation of Chenopodium seeds through the destruction of other seeds of wild plants, such as those of Poaceae. Furthermore, Chenopodium is an indicator taxon for active or abandoned pastoral camps and it becomes more dominant in the vegetation communities around pastoralist sites in response to herding activities (Spengler et al. 2013b). Dung is full of plant nutrients and laden with scarified Chenopodium seeds that have had their dormancy reduced by the digestion process. Therefore, this is one of the first plants to colonize a pastoral camp after the herd is moved on to new pastures; in fact, abandoned camps from previous years are often identifiable by the dense communities of Chenopodium plants growing there.

\section{Conclusions}

We can rarely separate out the exact suite of depositional processes that contributed to the introduction of the seeds from wild herbaceous plants to archaeological sites, including seed rain, bioturbation, dung burning as fuel and human foraging. As many researchers have observed, "the source of 'likely dung seeds' cannot be unequivocally assigned to the burning of dung" (Hastorf and Wright 1998, p 222); likewise, human and animal foraging practices can create similar macrobotanical assemblages. However, it is clear that seeds are readily incorporated into fires when dung that is laden with seeds is burned for fuel, and the implications of this fact have profound ramifications on the field of archaeobotany. In the absence of specific evidence to support another means of introduction, it is easier to argue that small seeds from wild herbaceous plants are from dung, seeing that "intentionally burned materials were more likely to have been put in a fire than accidentally burned ones, and fuel is one of the few things routinely and necessarily put in fire" (Miller 1996, p 526). Hence, archaeobotanists wishing to argue for other interpretations of their data, such as human foraging or agricultural field weeds, need to focus on context, such as good evidence in the form of a cache of wild seeds in a storage pit or in a pottery vessel. Seeds in middens or in the general stratigraphy or fill are more likely to represent ash from a fire and therefore fuel remains (Smith et al. 2015). However, there are many other ways of introduction that have not been explored in full, for example animal-dispersed seeds such as Galium which could enter an archaeological site attached to the fur, wool or hair of herd animals. Burning brush, dried grasses and forbs (non-grass herbs), or sod and dried steppe biomass as a fire starter or fuel could incorporate seeds. Furthermore, starting fires on top of organic-rich soil could lead to the charring of the soil seed bank and 
cause the incorporation of immense quantities of seeds into an assemblage.

There are several key observations that have powerful impacts on Eurasian macrobotanical studies that I will conclude this paper with. First, dung burning has the potential to dramatically overshadow the archaeological visibility of other economic activities, especially if grain processing or foraging occurred seasonally or if foddering was done with millets or free-threshing cereals. Not only are cereal grains destroyed by the digestion process, but seeds of certain kinds of wild herbaceous plants are often largely overrepresented in dung burning assemblages. Dung collecting and burning are usually daily activities, and daily activities are far more likely to be represented in the archaeological record than periodic or seasonal activities, such as grain processing. Second, as experimental work by Schepers and van Haaster (2015) has shown, the density and abundance counts of seeds of wild herbaceous plants in dung burning assemblages do not reflect the population percentages of the plants grazed by herd animals. Notably, in archaeobotanical assemblages, endozoochorously dispersed seeds such as Chenopodium are highly over-represented and are greatly concentrated by digestion, mastication, carbonization and organic degradation. Seed densities in dung are also skewed by plants which produce many seeds, and by seed size biases due to ungulate digestion. Third, the strong signature of burned dung in archaeobotanical assemblages across most of Eurasia means that it is usually impossible to disentangle the exact means of introduction for small $(<2 \mathrm{~mm})$ seeds of wild herbaceous plants, so it is not possible to discuss with confidence topics such as agricultural field weeds and human foraging of small seeds, unless highly specific 'smokinggun' assemblages are recovered.

Acknowledgements Open access funding provided by Max Planck Society. I would like to thank John (Mac) Marston, Chantel White and Alan Farahani, the session organizers, for inviting me to write this paper, and Naomi Miller for inspiring the paper through her research. I would also like to thank Naomi for laying down a research foundation that I have built my own career on.

Open Access This article is distributed under the terms of the Creative Commons Attribution 4.0 International License (http://creativeco mmons.org/licenses/by/4.0/), which permits unrestricted use, distribution, and reproduction in any medium, provided you give appropriate credit to the original author(s) and the source, provide a link to the Creative Commons license, and indicate if changes were made.

\section{References}

Anderson EN (2014) Food and environment in early and medieval China. University of Pennsylvania Press, Philadelphia
Anderson S, Ertug-Yaras F (1996) Fuel, fodder and faeces: An ethnographic and botanical study of dung fuel use in central Anatolia. Environ Archaeol 1:99-108

Anthony DW, Brown D, Brown E et al (2005) The Samara valley project: late bronze age economy and ritual in the Russian steppes. Eurasia Antiqua 11:395-417

Bembo A (2007) [1672]) The travels and journal of Ambrosio Bembo. University of California Press, London

Bogaard A, Fraser R, Heaton THE et al (2013) Crop manuring and intensive land management by Europe's first farmers. Proc Natl Acad Sci USA 110:12,589-12,594

Bogaard A, Heaton THE, Poulton PR, Merbach I (2007) The impact of manuring on nitrogen isotope ratios in cereals: Archaeological implications for reconstruction of diet and crop management practices. J Archaeol Sci 34:335-343

Bokovenkov N (2006) The emergence of the Tagar culture. Antiquity $80: 860-879$

Bottema S (1984) The composition of modern charred seed assemblages. In: Van Zeist W, Casparie WA (eds) Plants and ancient man: studies in palaeoethnobotany. Balkema, Rotterdam, pp 207-212

Braadbaart F, Poole I, Huisman HDJ, van Os B (2012) Fuel, fire and heat: an experimental approach to highlight the potential of studying ash and char remains from archaeological contexts. J Archaeol Sci 39:836-847

Brochier JE, Villa P, Giacomarra M (1992) Shepherds and sediments: geo-ethnoarchaeology of pastoral sites. J Anthropol Archaeol 11:47-102

Bull ID, Simpson IA, Van Bergen PF, Evershed RP (1999) Muck 'n' molecules: organic geochemical methods for detecting ancient manuring. Antiquity 73:86-96

Burnes A (1834) Travels into Bokhara: being the account of a journey from India to Cabool, Tartary and Persia. John Murray, London

Canti MG (1997) An investigation of microscopic calcareous spherulites from herbivore dung. J Archaeol Sci 24:219-231

Canti MG (1999) The production and preservation of faecal spherulites: animals, environment and taphonomy. J Archaeol Sci 26:251-258

Charles M (1998) Fodder from dung: the recognition and interpretation of dung-derived plant material from archaeological sites. Environ Archaeol 1:111-122

Cohen MN, Armelagos GJ (eds) (1984) Paleopathology at the origins of agriculture. Academic Press, Orlando

Crowther J (2002) The experimental earthwork at Wareham, Dorset after 33 years: retention and leaching of phosphate released in the decomposition of buried bone. J Archaeol Sci 29:405-411

Cunningham A (1854) Ladak, physical, statistical and historical. Allen, London

Derreumaux M (2005) How to detect fodder and litter? A case study from the roman site 'Le Marais de Dourges', France. Veget Hist Archaeobot 14:373-385

Doughty CM (1921) Travels in Arabia Desert, vol 1. Warner, London

Doumani PN, Frachetti MD, Beardmore R, Schmaus T, Spengler RN, Mar'yashev AN (2015) Bronze Age mountain agriculture, funerary ritual, and mobile pastoralism at Tasbas, southeastern Kazakhstan. Archaeol Res Asia 1-2:17-32

Eksambekar SP, Kajale MD (2007) Phytolith analysis for understanding formation processes at Neolithic Budhial, district Gulbarga, South India. In: Paddayya K, Jhaldiyal R, Sushama GD (eds) Formation processes and Indian archaeology. Deccan College Post Graduate and Research Institute, Pune, pp 267-277

Ekvall RB (1968) Fields on the hoof: nexus of Tibetan nomadic pastoralism. Holt, Reinhart and Winston

Elliott S, Bendrey R, Whitlam J, Aziz KR, Evans J (2015) Preliminary ethnoarchaeological research on modern animal husbandry in 
Bestansur, Iraqi Kurdistan: integrating animal, plant and environmental data. Environ Archaeol 20:283-303

Evershed RP, Bethell PH, Reynolds PJ, Walsh NJ (1997) $5[\beta]$-Stigmastanol and related $5[\beta]$-Stanols as biomarkers of manuring: analysis of modern experimental material and assessment of the archaeological potential. J Archaeol Sci 24:485-495

Féaux de la Croix J (2016) Iconic places in Central Asia: The moral geography of dams, pastures and holy sites. Transcript, Bielefeld

Flannery KV (1969) Origins and ecological effects of early domestication in Iran and the Near East. In: Ucko PJ, Dimbleby GW (eds) The domestication and exploitation of plants and animals. Duckworth, London, pp 73-100

Frachetti MD, Spengler RN, Fritz JF, Mar'yashev AN (2010) Earliest direct evidence for broomcorn millet and wheat in the central Eurasian steppe region. Antiquity 84:993-1,010

Ghosh R, Gupta S, Bera S, Jiang HE, Li X, Li CS (2008) Ovi-caprid dung as an indicator of paleovegetation and paleoclimate in northwestern China. Quat Res 70:149-157

Hall AR, Kenward HK (1998) Disentangling dung: pathways to stable manure. Environ Archaeol 1:123-126

Harris M (2000) India's sacred cow. In: Goodman AH, Dufur DL, Pelto GH (eds) Nutritional anthropology: biocultural perspectives on food and nutrition. Mayfield, Mount View, pp 113-118

Hastorf CA, Wright MF (1998) Interpreting wild seeds from archaeological sites: a dung charring experiment from the Andes. J Ethnobiol 18:211-227

Helbæk H (1969) Plant collecting, dry-farming, and irrigation in prehistoric Deh Luran. In: Hole F, Flannery KV, Neely JA (eds) Prehistory and human ecology of the Deh Luran plain. University of Michigan Museum of Anthropology Memoir 1) University of Michigan, Ann Arbor, pp 383-426

Hillman GC, Colledge SM, Harris DR (1989) Plant-food economy during the Epipaleolithic period at Tell Abu Hureyra, Syria: dietary diversity, seasonality, and modes of exploitation. In: Harris DR, Hillman GC (eds) Foraging and farming: the evolution of plant exploitation. pp 240-268. Unwin Hyman, London

Hillman GC, Legge AJ, Rowley-Conwy PA (1997) On the charred seeds from epipalaeolithic abu Hureyra: food or fuel? Curr Anthropol 38:651-655

Hitchcock AS (1951) Manual of the grasses of the United States. United States Government Printing Office, Washington DC

Holliday VT (2004) Soils in archaeological research. Oxford University Press, New York

Holliday VT, Gartner WG (2007) Methods of soil P analysis in archaeology. J Archaeol Sci 34:301-333

Huc ÉR (1860) Recollections of a journey through Tatary, Thibet, and China during the years 1844,1845 , and 1846 . Appleton, New York

Kawaguchi SE (1909) Three years in Tibet. Theosophist Publishing Society, London

Klinge J-A, Fall P (2010) Archaeobotanical inference of Bronze Age land use and land cover in the eastern Mediterranean. J Archaeol Sci 37:2,622-2,629

Kramer C (1982) Village ethnoarchaeology: rural Iran in archaeological perspective. Academic Press, New York

Lancelotti C, Madella M (2012) The "invisible" product: developing markers for identifying dung in archaeological contexts. J Archaeol Sci 39:953-963

Lewis O (1958) Village life in northern India. Vintage Books, New York

Linseele V, Marinova E, Van Neer W, Vermeersch PM (2010) Sites with Holocene dung deposits in the Eastern Desert of Egypt: visited by herders? J Arid Environ 74:818-828

Linseele V, Reimer H, Baeten J, De Vos D, Marinova E, Ottoni C (2013) Species identification of archaeological dung remains: a critical review of potential methods. Environ Archaeol 18:5-17
Lu H, Zhang J, Yang Y et al (2016) Earliest tea as evidence for one branch of the Silk Road across the Tibetan Plateau. Sci Rep $6: 18,955$

MacDonald D (1929) The land of the Lama. Seeley Service, London

Madella M (1997) Phytolith analysis from the Indus Valley site of Kot Diji, Sindh, Pakistan. In: Sinclair A, Slater E, Gowlett J (eds) Archaeological sciences 1995. Oxbow Press, Oxford, pp 294-302

Majak W, Brooke BM, Ogilvie RT (2008) Stock-poisoning plants of western Canada. Canadian Department of Agriculture, Ottawa

Marinova E, Ryan P, Van Neer W, Friedman R (2013) Animal dung from arid environments and archaeobotanical methodologies for its analysis: an example from animal burials of the Predynastic elite cemetery HK6 at Hierakonpolis, Egypt. Environ Archaeol 18:58-71

Matthews W (2010) Geoarchaeology and taphonomy of plant remains and microarchaeological residues in early urban environments in ancient Near East. Quat Int 214:98-113

Miller NF (1982) Economy and environment of Malyan: A third millennium BC urban center in southern Iran. Doctoral Dissertation, Anthropology Department, University of Michigan

Miller NF (1984) The use of dung as fuel: an ethnographic example and an archaeological application. Paléorient 10:71-79

Miller NF (1996) Seed eaters of the ancient Near East: human or herbivore. Curr Anthropol 37:521-528

Miller NF (1997) Reply. Curr Anthropol 38:655-659

Miller NF (2004) Long-term vegetation changes in the Near East. In: Redman CL, James SR, Fish PR, Rogers JD (eds) The archaeology of global change: the impact of humans on their environment. Smithsonian Institution Press, Washington, DC, pp 130-140

Miller NF (2009) From food and fuel to farms and flocks: the integration of plant and animal remains in the study of the agropastoral economy at Gordion, Turkey. Curr Anthropol 50:915-924

Miller NF, Gleason KL (1994) Fertilizer in the identification and analysis of cultivated soil. In: Miller NF, Gleason KL (eds) The archaeology of garden and field. University of Pennsylvania Press, Philadelphia

Miller NF, Marston JM (2012) Archaeological fuel remains as indicators of ancient West Asian agropastoral and land-use systems. J Arid Environ 86:97-103

Miller NF, Smart TL (1984) Intentional burning of dung as fuel: A mechanism for the incorporation of charred seeds into the archaeological record. J Ethnobiol 4:15-28

Minnis PE (1981) Seeds in archaeological sites: sources and some interpretive problems. Am Antiquity 46:143-152

Motuzaite-Matuzeviciute G, Telizhenko S, Jones MK (2012) Archaeobotanical investigation of two Scythian-Sarmatian period pits in eastern Ukraine: implications for floodplain cereal cultivation. J Field Archaeol 37:51-61

O'Donovan E (1883) Merv: A story of adventures and captivity epitomized from "the Merv Oasis". Smith, Elder, London

Pearsall D (1988) Interpreting the meaning of macroremain abundance: the impact of source and context. In: Hastorf CA, Popper VS (eds) Current paleoethnobotany: analytical methods and cultural interpretations of archaeological plant remains. University of Chicago Press, Chicago, pp 97-118

Poklonskii VL, Pripuzov NP, Stenin PV, Ovchinnikov M (1953) [1897]) Yakut ethnographic sketches. Human Relations Area Files, New Haven

Popova LM (2006) Political pastures: Navigating the steppe in the middle Volga region (Russia) during the Bronze Age. Unpublished Doctoral Dissertation, University of Chicago, 2006

Powers AH, Padmore J, Gilbertson DD (1989) Studies of late prehistoric and modern opal phytoliths from coastal sand dunes and Machair in Northwest Britain. J Archaeol Sci 16:27-45 
Reddy SN (1999) Fueling the hearths of India: The role of dung in paleoethnobotanical interpretations. Paléorient 24:61-70

Reinhard KJ (1992) Parasitology as an interpretative tool in archaeology. Am Antiquity 57:231-245

Rhode D, Madsen DB, Brantingham PJ, Dargye T (2007a) Yaks, yak dung, and prehistoric human habitation of the Tibetan Plateau. Dev Quat Sci 9:205-224

Rhode D, Zhang H, Madsen DB, Xing G, Brantingham PJ, Ma H, Olsen JW (2007b) Epipaleolithic/early neolithic settlements at Qinghai Lake, west China. J Archaeol Sci 34:600-612

Roberts MF, Wink M (1998) Alkaloids: biochemistry, ecology, and medical applications. Plenum Press, New York

Rühl L, Herbig C, Stobbe A (2015) Archaeobotanical analysis of plant use at Kamennyi Ambar, a Bronze Age fortified settlement of the Sintashta culture in the southern Trans-Urals steppe, Russia. Veget Hist Archaeobot 24:413-426

Rye OS, Evans C (1976) Traditional pottery techniques of Pakistan. Smithsonian Institute Press, Washington DC (Smithsonian contributions to anthropology 21)

Schelvis J (1992) The identification of archaeological dung deposits on the basis of remains of predatory mites (Acari; Gamasida). J Archaeol Sci 19:677-682

Schepers M, Van Haaster H (2015) Dung matters: An experimental study into the effectiveness of using dung from hay-fed livestock to reconstruct local vegetation. Environ Archaeol 20:66-81

Schuyler E (1877) Turkistan: Notes of a journey in Russian Turkistan, Khokand, Bukhara, and Kuldja, vol 1. Scribner, Armstrong, New York

Shahack-Gross R (2011) Herbivorous livestock dung: Formation, taphonomy, methods for identification, and archaeological significance. J Archaeol Sci 38:205-218

Shahack-Gross R, Albert R-M, Gilboa A, Nagar-Hilman O, Sharon I, Weiner S (2005) Geoarchaeology in an urban context: The uses of space in a Phoenician monumental building at Tel Dor (Israel). J Archaeol Sci 32:1,417-1,431

Shahack-Gross R, Finkelstein I (2008) Subsistence practices in an arid environment: a aeoarchaeological investigation in an Iron Age site, the Negev highlands, Israel. J Archaeol Sci 35:965-982

Shelach-Lavi G (2015) The archaeology of early China: from prehistory to the han dynasty. Cambridge University Press, Cambridge

Shillito LM, Bull ID, Matthews W, Almond MJ, Williams JM, Evershed RP (2011) Biomolecular and micromorphological analysis of suspected faecal deposits at Neolithic Çatalhöyük, Turkey. J Archaeol Sci 38:1,868-1,877

Sillar B (2000) Dung by preference: The choice of fuel as an example of how Andean pottery production is embedded within wider technical, social and economic practices. Archaeometry 42:43-60

Simpson IA, Dockrill SJ, Bull ID, Evershed RP (1998) Early anthropogenic soil formation at Tofts Ness, Sanday, Orkney. J Archaeol Sci 25:729-746

Simpson IA, Van Bergen PF, Perret V, Elhmmali MM, Roberts DJ, Evershed RP (1999) Lipid biomarkers of manuring practice in relict anthropogenic soils. Holocene 9:223-229

Smith A, Dotzel K, Fountain J, Proctor L, Von Baeyer M (2015) Examining fuel use in antiquity: archaeobotanical and anthracological approaches in southwest Asia. J Ethnobiol 6:192-194

Smith P, Young TC (1983) The force of numbers; population pressure in central western Zagros, 12000-4500 BC. In Young TC, Smith PEL (eds) The hilly flanks: essays on the prehistory of southwestern Asia presented to Robert J. Braidwood (Studies in Ancient Oriental Civilizations 36) Chicago, The Oriental Institute of the University of Chicago, pp 141-161
Song J, Lu H, Zhang Z, Liu X (2017) Archaeobotanical remains from the mid-first millenniumAD site of Kaerdong in western Tibet. Archaeol Anthropol Sci. https://doi.org/10.1007/s1252 0-017-0521-6

Spengler RN, III (2013) Botanical resource use in the Bronze and Iron Age of the central Eurasian mountain/steppe interface: Decision making in multi-resource pastoral economies. Doctoral dissertation for the Anthropology Department at Washington University in St. Louis

Spengler RN, III (2014) Niche dwelling vs. niche construction: landscape modification in the Bronze and Iron Ages of Central Asia. Hum Ecol 42:813-821

Spengler RN III, Chang C, Tourtellotte PA (2013a) Agricultural production in the Central Asian mountains: Tuzusai, Kazakhstan (410-150 вC). J Field Archaeol 38:68-85

Spengler RN, Frachetti MD, Doumani PN, Rouse LM, Cerasetti B, Bullion E, Mar'yashev AN (2014) Early agriculture and crop transmission among Bronze Age mobile pastoralists of Central Eurasia. Proc R Soc B 281:20133382

Spengler RN III, Frachetti MD, Fritz GJ (2013b) Ecotopes and herd foraging practices in the Bronze and Iron Age, steppe and mountain ecotone of Central Asia. J Ethnobiol 33:125-147

Stegelmeier BL, Lee ST, James LF, Gardener DR, Panter KE, Ralphs MH, Pfister JA (2007) Cutleaf nightshade (Solanum triflorum Nutt.) toxicity in horses and hamsters. In: Panter KE, Wierenga TL, Pfister JA (eds) Poisonous plants: global research solutions. CABI Publishing, Wallingford, pp 296-300

Stiner MC (2001) Thirty years on the "broad spectrum revolution" and paleolithic demography. Proc Natl Acad Sci 98:6,993-6,996

Teichman E (1921) Travels of a consular officer in northwest China. Cambridge University Press, Cambridge

Valamoti SM (2007) Detecting seasonal movement from animal dung: an investigation in Neolithic northern Greece. Antiquity $81: 1,053-1,064$

Valamoti SM (2013) Towards a distinction between digested and undigested glume bases in the archaeobotanical record from Neolithic northern Greece: a preliminary experimental investigation. Environ Archaeol 18:31-42

Valamoti SM, Charles M (2005) Distinguishing food from fodder through the study of charred plant remains: An experimental approach to dung-derived chaff. Veget Hist Archaeobot 14:528-533

Van Geel B (2001) Non-pollen palynomorphs. In: Smol J, Birks J, Last W (eds) Tracking environmental changes using lake sediments, vol 3. Terrestrial, algal and siliceous indicators. Kluwer Academic Press, Dordrecht, pp 99-119

Vaňkát A, Krepl V, Kára J (2010) Animal dung as a source of energy in remote areas of Indian Himalayas. Agricult Trop Subtrop 43:140-142

Veal R (2013) Fueling ancient Mediterranean cities: A framework for charcoal research. In: Harris WV (ed) The ancient Mediterranean environment between science and history. Brill, Leiden, pp 37-58

Wallace M, Charles M (2013) What goes in doesn't always come out: the impact of the ruminant digestive system of sheep on plant material, and its importance for the interpretation of dung-derived archaeobotanical assemblages. Environ Archaeol 18:18-30

Watson PJ (1979) Archaeological ethnography in western Iran. University of Arizona Press, Tucson

Zeder MA (2012) The broad spectrum revolution at 40: resource diversity, intensification, and an alternative to optimal foraging explanations. J Anthropol Archaeol 31:241-264 